\title{
RECENT OBSERVATIONS OF THE MOTTLED DUSKYWING IN SANDILANDS PROVINCIAL FOREST, MANITOBA
}

\section{Deanna Dodgson}

544 Helmsdale Ave.

Winnipeg, MB R2K OW6

ddodgson@shaw.ca

Mottled Duskywing (Erynnis

martialis) is a distinctively patterned, early-season spread-wing skipper that, depending on the jurisdiction, is considered locally uncommon, declining, rare or extirpated throughout its North American range. In 2012, The Committee on the Status of Endangered Wildlife in Canada designated the Great Lakes and Boreal populations of Mottled Duskywing as Endangered (Conservation Ranking S2). ${ }^{1}$

Following a reassessment of the provincial status of Lepidoptera in 2015, the Manitoba Conservation Data Centre changed the conservation ranking from $\mathrm{S} 2$ to S1 (based on the species' limited distribution and small number of occurrences). ${ }^{2}$

In Manitoba, Narrow-leaved New Jersey Tea (Ceanothus herbaceous), is their sole larval foodplant (Figure 1). Alternate common names include Prairie Redroot and Inland New Jersey Tea. C. herbaceous is a perennial woody shrub in the Buckthorn family (Rhamnaceae) that grows up to three feet tall, has finely serrated leaves and bears clusters of whitish flowers. The plant is found in semi-open to open areas in dry, sandy locations. The greatest known concentrations of $C$. herbaceus are found in Sandilands Provincial Forest, in the southeastern corner of the province.

A relatively large population of C. herbaceus (exceeding 500 plants) grows along an $11 \mathrm{~km}$ section of Provincial Road 503 in Sandilands Provincial Forest, south of East
Braintree. Plants were distributed in loose clusters or dense groups, these often connected by a varying number of scattered individual plants. The right-of-way along this stretch of road is wide and plants were located from the road's edge to the forest margin.

Encouraged by the abundance of the foodplant, Garry Budyk and I informally surveyed the area for the skipper on June 24, 2019. Reaching a maximum temperature of $24^{\circ} \mathrm{C}$, the day was mainly overcast with a light wind. Between 11:00h and 15:30h, we made 10 stops along the road, each at least $0.25 \mathrm{~km}$ apart. Duration of stops varied from 20 to 45 minutes. Identifications of skippers and butterflies present were made as they basked on the ground or on the tips of twigs, or as they nectared. Stepping carefully between the host plants encouraged

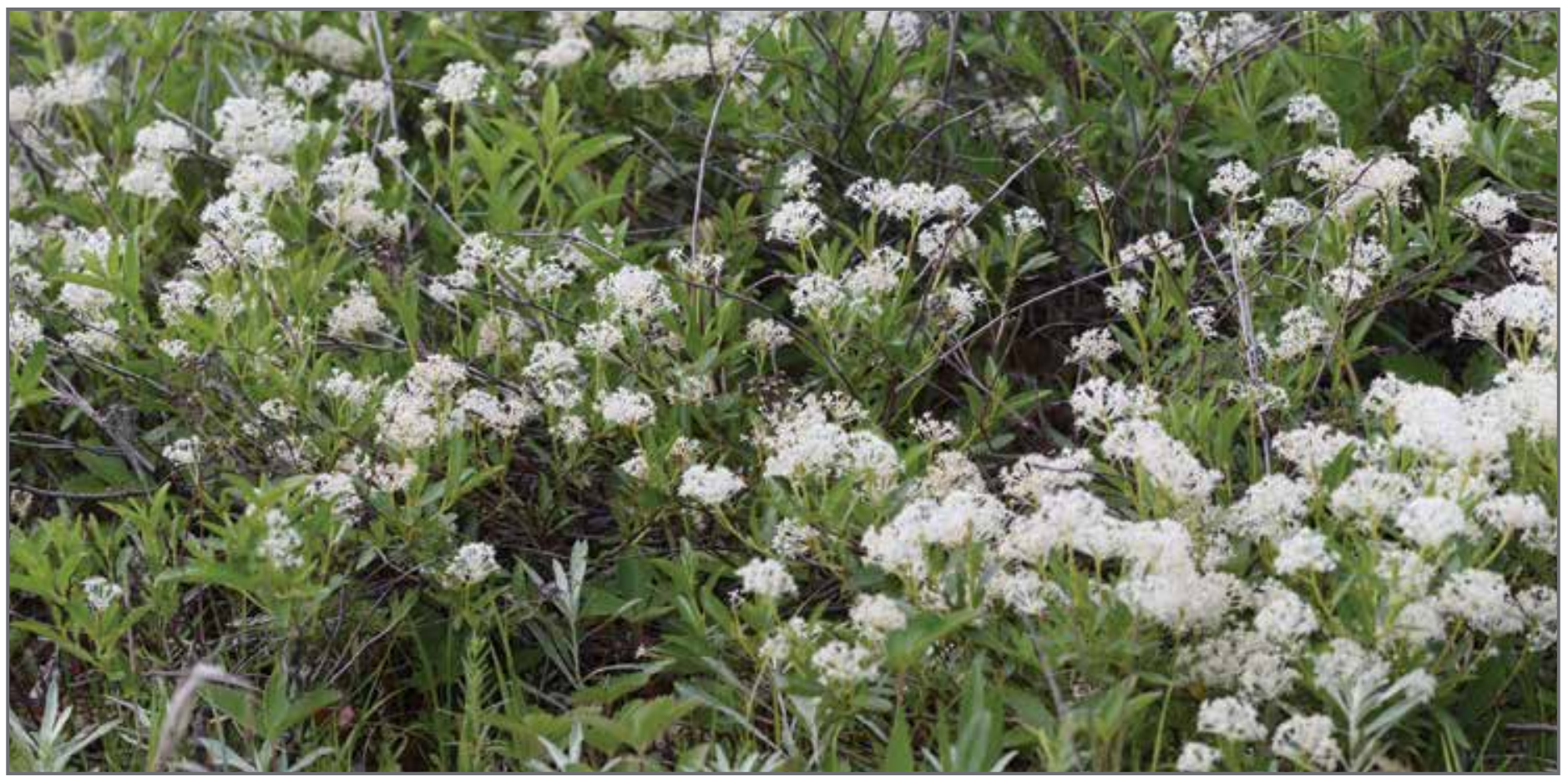

FIGURE 1. Narrow-leaved New Jersey Tea, larval food plant of Mottled Duskywing. Photo credit: Deanna Dodgson. 
less active individuals to flush, allowing better views. Northern Cloudywing and several butterfly species (Canadian Tiger Swallowtail, Silver-bordered Fritillary, Northern Crescent,Viceroy, Painted Lady, White Admiral and Monarch) were recorded in addition to Mottled Duskywing.

All but one stop produced two or more Mottled Duskywings. Totals per stop were based on the highest number of individuals seen simultaneously (Table 1). By day's end, we had counted 21 Mottled Duskywings (17 males and four females) (Figures 2,3). Unidentified duskywings were seen at several locations so the total number may have been higher. Photographs of at least one Mottled Duskywing were taken at most stops, and all data were submitted to the Manitoba Conservation Data Centre's "All Manitoba Nature" project on iNaturalist. ${ }^{3}$

Behaviours of Mottled Duskywings were much the same as described in the literature, with males being quite active, flying to and fro as they presumably searched for females among the clumps of C. herbaceous, or interacting with other skippers and butterflies passing by. The females were generally more sedentary, remaining near the host plants. Both sexes were observed nectaring on the foodplants, and one female was seen in the act of ovipositing. Damp patches of soil at which to observe

\section{TABLE 1. Summary of Survey Results}

\begin{tabular}{|c|c|c|}
$\begin{array}{c}\text { STOP } \\
\text { NUMBER }\end{array}$ & COORDINATES (NAD83) & $\begin{array}{c}\text { NUMBER } \\
\text { OF MD }\end{array}$ \\
\hline 1 & $49.55682 \mathrm{~N} /-95.74183 \mathrm{~W}$ & 2 \\
\hline 2 & & 2 \\
\hline 3 & & 2 \\
\hline 4 & & 2 \\
\hline 5 & & 3 \\
\hline 6 & & 3 \\
\hline 7 & & 2 \\
\hline 8 & & 1 \\
\hline 9 & & 2 \\
\hline 10 & $49.58361 \mathrm{~N} /-95.86553 \mathrm{~W}$ & 2 \\
\hline
\end{tabular}

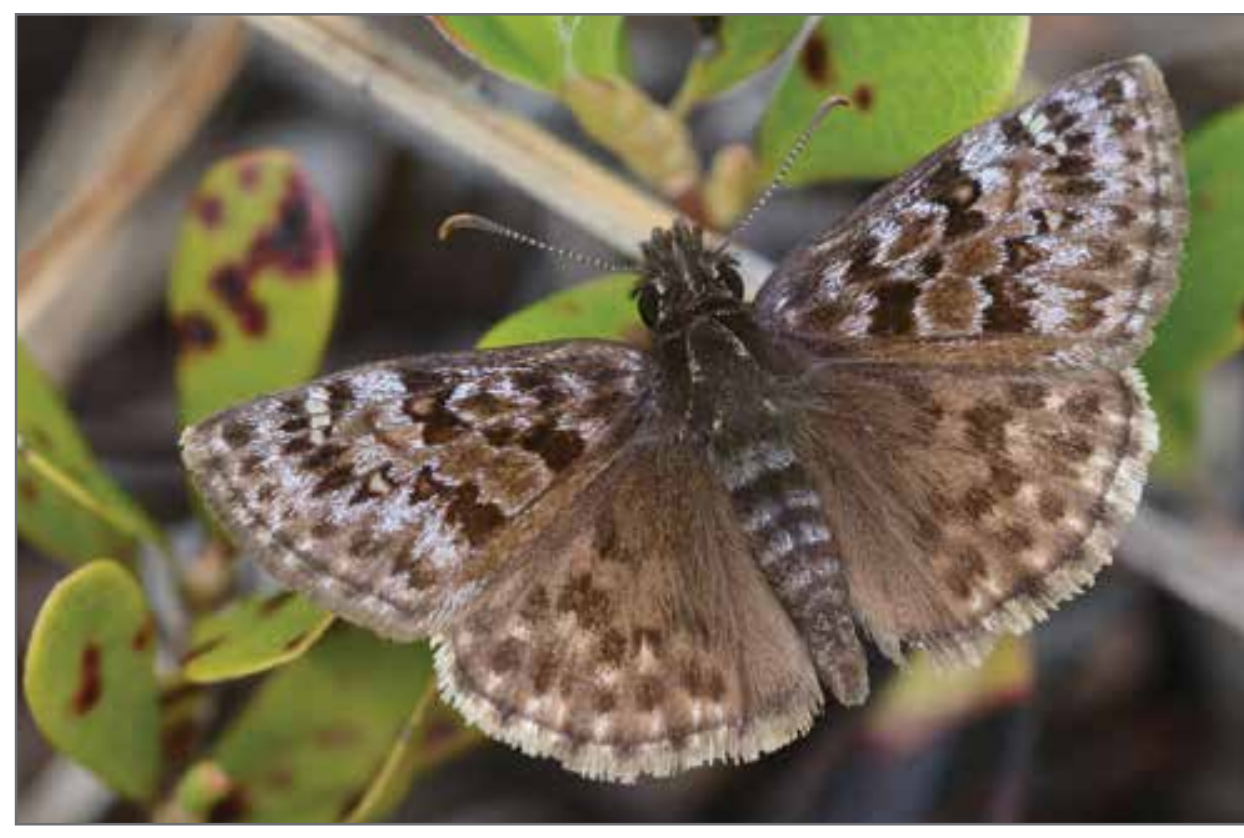

FIGURE 2. Mottled Duskywing male, basking. Photo credit: Deanna Dodgson

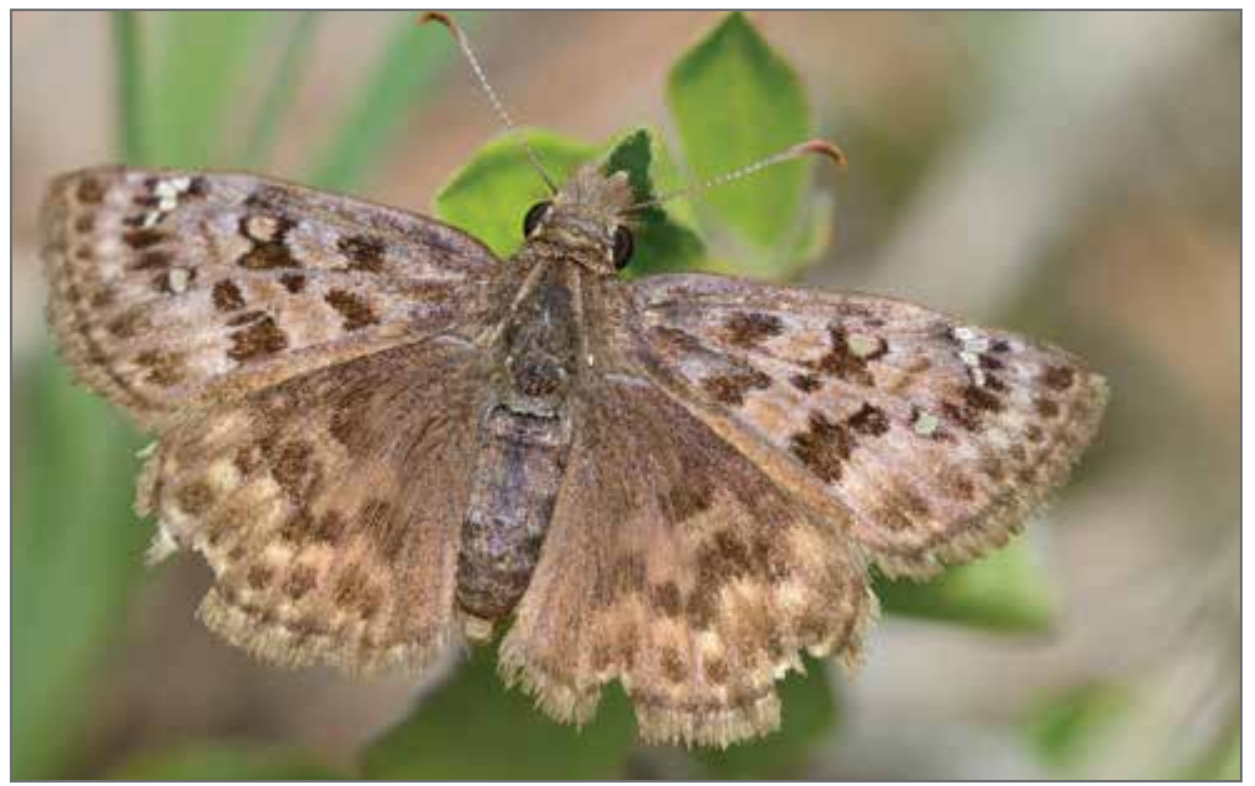

FIGURE 3. Worn female Mottled Duskywing. Photo credit: Deanna Dodgson.

puddling lepidopterans were entirely lacking.

In the 10 seasons in which we have observed Mottled Duskywings in Sandilands Provincial Forest, this marks the first time that we have detected more than five individuals in one small area in a single day.

\section{Acknowledgements}

Thanks to Peter Taylor, Larry de March and John Acorn for helpful comments and suggestions on drafts of the article.
1. COSEWIC. 2012. COSEWIC assessment and status report on the Mottled Duskywing Erynnis martialis in Canada. Committee on the Status of Endangered Wildlife in Canada. Ottawa. xiv + 35 pp. (www. registrelep-sararegistry.gc.ca/default_e.cfm).

2. Conservation Data Centre, Manitoba Sustainable Development (2017). Query of biodiversity database (Biotics) for species at risk and other rare species occurrences within Manitoba. Conducted May 2017.

3. URL: https://inaturalist.ca/projects/allmanitoba-nature 